\title{
Population-wide weight loss and regain in relation to diabetes burden and cardiovascular mortality in Cuba 1980-2010: repeated cross sectional surveys and ecological comparison of secular trends
}

\author{
(c) $\frac{(1)(8)}{\mathrm{gy} \text { ne }}$ OPEN ACCESS
}

Manuel Franco associate professor ${ }^{1}$ adjunct associate professor ${ }^{2}$ visiting researcher ${ }^{3}$, Usama Bilal research assistant ${ }^{1}$ visiting researcher ${ }^{3}$, Pedro Orduñez regional adviser ${ }^{4}$ professor $^{5}$, Mikhail Benet professor $^{5}$, Alain Morejón assistant professor ${ }^{5}$, Benjamín Caballero professor ${ }^{6}$, Joan F Kennelly research assistant professor ${ }^{7}$, Richard S Cooper professor and chair ${ }^{8}$

${ }^{1}$ Social and Cardiovascular Epidemiology Research Group, School of Medicine, University of Alcalá, Alcalá de Henares, Madrid, Spain; ${ }^{2}$ Department of Epidemiology, Johns Hopkins Bloomberg School of Public Health, Baltimore, MD, USA; ${ }^{3}$ Department of Epidemiology, Atherothrombosis and Cardiovascular Imaging, Centro Nacional de Investigaciones Cardiovasculares Madrid, Spain; ${ }^{4}$ Project for Chronic Disease Prevention and Control, Pan American Health Organization, Washington, DC, USA; ${ }^{5}$ Centro de Estudios sobre Enfermedades Crónicas, Universidad de Ciencias Médicas, Cienfuegos, Cuba; ${ }^{6}$ Center for Human Nutrition, Department of International Health, Johns Hopkins Bloomberg School of Public Health, USA; ${ }^{7}$ Division of Community Health Sciences, University of Illinois at Chicago School of Public Health, Chicago, IL, USA; ${ }^{8}$ Department of Public Health Sciences, Loyola University Stritch School of Medicine, Maywood, IL, USA

\begin{abstract}
Objective To evaluate the associations between population-wide loss and gain in weight with diabetes prevalence, incidence, and mortality, as well as cardiovascular and cancer mortality trends, in Cuba over a 30 year interval.

Design Repeated cross sectional surveys and ecological comparison of secular trends.

Setting Cuba and the province of Cienfuegos, from 1980 to 2010.

Participants Measurements in Cienfuegos included a representative sample of 1657, 1351, 1667, and 1492 adults in 1991, 1995, 2001, and 2010 , respectively. National surveys included a representative sample of 14304,22851 , and 8031 participants in 1995, 2001, and 2010, respectively.

Main outcome measures Changes in smoking, daily energy intake, physical activity, and body weight were tracked from 1980 to 2010 using national and regional surveys. Data for diabetes prevalence and incidence were obtained from national population based registries. Mortality trends were modelled using national vital statistics.

Results Rapid declines in diabetes and heart disease accompanied an average population-wide loss of $5.5 \mathrm{~kg}$ in weight, driven by an economic crisis in the mid-1990s. A rebound in population weight followed in 1995
\end{abstract}

(33.5\% prevalence of overweight and obesity) and exceeded pre-crisis levels by 2010 (52.9\% prevalence). The population-wide increase in weight was immediately followed by a $116 \%$ increase in diabetes prevalence and $140 \%$ increase in diabetes incidence. Six years into the weight rebound phase, diabetes mortality increased by $49 \%$ (from 9.3 deaths per 10000 people in 2002 to 13.9 deaths per 10000 people in 2010). A deceleration in the rate of decline in mortality from coronary heart disease was also observed.

Conclusions In relation to the Cuban experience in 1980-2010, there is an association at the population level between weight reduction and death from diabetes and cardiovascular disease; the opposite effect on the diabetes and cardiovascular burden was seen on population-wide weight gain.

\section{Introduction}

It was recognised early in the course of the global epidemic of type 2 diabetes that variation in the prevalence of the disease among populations could be explained largely by relative weight. ${ }^{1}$ This observation is supported by survey research from virtually every country in the World Health Organization database. ${ }^{2}$ Despite predictions on the effect of the obesity and diabetes epidemics on life expectancy, ${ }^{3}$ it is unclear to what 
extent they can alter the downward trend of cardiovascular diseases prevalence observed in many countries. ${ }^{4}$ Furthermore, lack of adequate data for public health precludes the empirical assessment of comparable trends across the developing world. Most cohort studies have suggested a "U" shaped association between body mass index and mortality, with the lowest point in the index range of 24 to $29 .{ }^{56}$ Therefore, key unknown factors are the net health impact of a given downward shift in the distribution of body mass index in a population, and the time lag between changes in body mass index and in the prevalence of non-communicable disease. ${ }^{?}$

Marked and rapid reductions in mortality from diabetes and coronary heart disease were observed in Cuba after the profound economic crisis of the early 1990s. ${ }^{8}$ These trends were associated with the declining capacity of the Cuban economy to assure food and mass transportation in the aftermath of the dissolution of the former Soviet Union and the tightening of the US embargo. Severe shortages of food and gas resulted in a widespread decline in dietary energy intake and increase in energy expenditure (mainly through walking and cycling as alternatives to mechanised transportation).

The largest effect of this economic crisis occurred over a period of about five years (1991-95, the so called "special period"), resulting in an average weight loss of 4-5 kg across the adult population. ${ }^{8}$ This economic crisis was not a full disruption of previous routines of daily life, but was actually characterised by its slow process of economic decline. During these years, the whole population continued to meet responsibilities in relation to work, school, and other social aspects, and the Ministry of Public Health maintained its regular surveillance system activities. ${ }^{9}{ }^{10}$

Since then, the Cuban economy has shown a modest but constant recovery, especially after the year 2000. ${ }^{11}{ }^{12}$ In fact, surveys have shown that the prevalence of obesity has now exceeded pre-crisis levels. ${ }^{13}$ The table $\Downarrow$ shows basic sociodemographic and economic information on Cuba before, during, and after the economic crisis.

To advance the prevention of non-communicable diseases, population-wide data remain crucial. Comparing disease rates over time, in relation to changes in risk factor levels in the population, indicates the extent to which disease can be prevented and what the most important risk factors are at the population level. ${ }^{14}$ The population preventive approach articulated by Geoffrey Rose in his seminal paper, ${ }^{15}$ is of importance when preventing and controlling non-communicable diseases, particularly cardiovascular diseases. The current study exemplifies a unique situation where population-wide body weight changed considerably, as a result of the combined and sustained effect of reduced energy intake and elevated physical activity. This scenario allowed us to assess its effect on diabetes and cardiovascular disease. ${ }^{16}$

Our objective was to examine the effect of population-wide changes in body weight—over a full cycle of weight loss and regain - on diabetes incidence, prevalence, and mortality in Cuba, from 1980 to 2010 . We also assessed the effects of this weight change cycle on rates of death from cardiovascular disease, cancer, all causes.

\section{Methods}

To study the population-wide changes in body weight over time, we used four cross sectional surveys in the city of Cienfuegos, on the southern coast of Cuba. These surveys are part of the Project of Cienfuegos, an initiative designed to study the risk factors for non-communicable diseases in Cuba.
To obtain all available data from government and published sources on mortality, physical activity, energy intake, and smoking in Cuba between 1980 and 2011, we did a systematic search. We used the following databases: Medline, Spanish Bibliographic Index in Health Sciences (IBECS), and the Scientific Library Online (BVS-SciELO Cuba), which includes most Cuban journals. Web appendix 1 details the 12 references included.

\section{Height, weight or overweight, and obesity}

The four cross sectional surveys measured height and weight, on the basis of stratified probability samples from the urban population aged $15-74$ years. The surveys included 1657,1351 , 1667, and 1492 adults for the years 1991, 1995, 2001, and 2011, respectively. The age distribution of the population in Cienfuegos is similar to the general Cuban population (web appendix 2). We used the following categories for body mass index: underweight $(<18.5)$, normal weight $(18.5-<25)$, overweight $(25-<30)$, and obesity $(\geq 30)$. All participants in the four surveys signed the informed consent. The ethics committee of the University of Medical Sciences, Cienfuegos, approved protocols.

\section{Physical activity}

Measures of self reported physical activity were available from representative samples of the population in Havana in 1987, 1988, and 1994 and from the national surveys on risk factors and chronic diseases (conducted nationally in 1995, 2001, and 2010, respectively). In these surveys, participants were designated as physically active if they engaged in regular physical activity, defined as 30 minutes of moderate or intense activity on at least five days per week.

\section{Energy intake}

The Food and Agriculture Organization of the United Nations provides disappearance data on energy intake per capita, by dividing total calories available for human consumption by the total population consuming the food supply during the reference period.

\section{Smoking}

National use of cigarettes per capita was calculated as the total number of cigarettes sold per year divided by the population aged 15 years and over. The prevalence of smoking was obtained from the national surveys on risk factors and chronic diseases conducted in 1995, 2001, and 2010, and other national studies previously conducted. We defined smoking as self reported current use of cigarettes or cigars (or both). ${ }^{17}$

\section{Diabetes prevalence and incidence}

In the Cuban national health system, the primary care doctor-nurse team is responsible for collecting health data for all residents in the neighbourhood of their catchment area (about 1500 individuals per team). One of the team activities organised by the health system is continuous assessment and risk evaluation (CARE, or Dispensarización in Spanish). ${ }^{18}{ }^{19}$ All households are visited at least once a year for a comprehensive health evaluation of the family, while patients with chronic diseases receive a visit at least once every three to six months. These health examinations covered $61.2 \%(n=5951088)$ of the population in $1979,{ }^{20} 75.9 \%(\mathrm{n}=7918647)$ in $1989,{ }^{20}$ and $98.2 \%$ $(\mathrm{n}=11038820)$ in $2009 .{ }^{21}$ We obtained data for diabetes prevalence and incidence from the CARE registries, spanning 
the time period of 1980-2009. ${ }^{20}{ }^{21}$ These registries allow the monitoring of chronic disease trends, such as diabetes incidence or prevalence.

\section{Mortality}

We obtained annual, age adjusted rates of mortality per 100000 people from the Cuban Ministry of Public Health. ICD-10 (international classification of diseases, 10th revision) codes were used for death from type 2 diabetes (E10-E14), coronary heart disease (I20-I25), stroke (I60-I69), cancer (C00-C97), and all causes for the period of 1980-2010. We used data from 1980 to examine possible trends unrelated to the economic crisis during the special period in 1991-95. The 1981 Cuban population census was used for age adjustment. Vital records in Cuba are essentially complete. Postmortem examinations in some hospitals include up to $85 \%$ of people coded as dying from cardiovascular disease, which provided considerable confidence in an accurate designation of the cause of death. ${ }^{22}$

\section{Statistical analysis}

To illustrate the distributions of body mass index in the four surveys from Cienfuegos (in 1991, 1995, 2001, and 2011), we used Stata SE version 12.1 to generate density plots through the Gaussian kernel function. To analyse changes in prevalence and mortality, joinpoint regression analysis was conducted using software developed by the Surveillance Research Program of the United States National Cancer Institute. ${ }^{23}$ This regression model allows identification of significant changes in linear trend slopes. The estimated annual change (\%) was then computed for each mortality trend by fitting a regression line to the natural logarithm of the rates within each period or phase.

We did not use this procedure to analyse diabetes incidence, owing to missing data from the years during the crisis. Because incidence estimates are inherently unstable, we enhanced visual presentation by constructing moving averages for each year with available data, using the incidence data from the previous, current, and following year.

\section{Results}

\section{Risk factor trends}

From its lowest point in the mid-1990s, average daily intake of energy per capita increased monotonically, reaching pre-crisis levels in 2002 and levelling off in 2005 (fig $1 \Downarrow$ ). On the other hand, physical activity had a slight downward trend after the mid-1990s, remaining stable from 2001, with more than half of the population being physically active. Although $80 \%$ of the population was classified as active in surveys conducted during the special period in $1991-95$, this proportion fell steadily in the last decade, and is currently at 55\% (fig 1). These population-wide changes in energy intake and physical activity were accompanied by large changes in body weight over this entire interval (figs $2 \Downarrow$ and $3 \Downarrow$ ).

Smoking prevalence (fig 1) slowly decreased during the 1980s and 1990 s (42\% in 1984, $37 \%$ in 1995), before declining more rapidly in the 2000 s ( $32 \%$ in $2001,24 \%$ in 2010). The number of cigarettes consumed per capita decreased during and shortly after the crisis. In 1990, 1934 cigarettes per capita were consumed (fig 1). This number changed to 1572,1196 , and 1449 cigarettes per capita in 1993, 1997, and 1999, respectively. Cigarette consumption has since remained stable.

Figure 2 depicts the distribution of body mass index from the Cienfuegos surveys of 1991, 1995, 2001, and 2010 with kernel density plots of each year's measurements. During the special period of 1991-95, there was a weight loss of $5.5 \mathrm{~kg}$ across the entire range of body mass index (that is, not only among obese people), with a mean reduction in body mass index of 1.5 units. After a period of economic recovery and stability, an increase in body mass index of 2.6 units was observed from 1995 to 2010; weight regain also occurred across the entire population, irrespective of body mass index. These distribution shifts in body mass index were consistent across surveys. The proportion of the population in the normal weight category decreased from $56.4 \%$ at the end of the special period in 1995 to $42.1 \%$ in 2010 . At the same time, proportions in the overweight and obesity categories increased by $19.4 \%$, from $33.5 \%$ in 1995 to $52.9 \%$ in 2010 (web appendix 3).

\section{Diabetes trends Diabetes prevalence and incidence}

Joinpoint regression analyses showed two different phases of diabetes prevalence (fig 3 ). The first phase had a slow and stable increase from 1980 (1.5 per 100 people) to 1997 (1.9 per 100 people), a total increase of $26.6 \%$ (2.9\% per year). In the second phase, diabetes prevalence increased from 1.9 per 100 people in 1997 to 4.1 per 100 people in 2009 and 2010, a total increase of $115.8 \%$ ( $6.3 \%$ per year).

Incidence of diabetes fluctuated widely (fig 3). For the decade before the crisis, incidence was stable, between 1980 (1.5 per 1000 people) and 1989 (1.8 per 1000 people). The only data point in the middle of the economic crisis showed a decrease in diabetes incidence, falling to 1.2 per 1000 people in 1992. For the years immediately after the crisis, incidence was lower than pre-crisis levels ( 1 per 1000 people in 1996 and $1997 v 1.4$ per 1000 people in 1999). Sharp increases were observed from 2000 onwards, peaking in 2002 (2.2 per 1000 people) and 2009 (2.4 per 1000 people). Thus, overall diabetes incidence decreased by $53 \%$ from its peak in the pre-crisis years (1986) to its lowest point after the crisis (1996 and 1997). Subsequently, incidence rose by $140 \%$ from 1996 to 2009.

\section{Diabetes mortality}

Joinpoint regression analysis of diabetes mortality showed four different phases (fig 3). The first phase, from 1980 to 1989 (pre-crisis years), was characterised by an increase of 60\% $(5.9 \%$ per year). The second phase from 1990 to 1996 overlapped with the special period in 1991-95, during which diabetes mortality stabilised (0.7\% decrease per year). However, from 1996 to 2002 , we recorded a decrease in diabetes mortality of $50 \%$ (13.95\% per year). Finally, from 2002 onwards, mortality rose by $49 \%$ (3.31\% per year; from 9.3 deaths per 10000 people in 2002 to 13.9 deaths per 10000 people in 2010), returning to pre-crisis rates.

\section{Mortality trends Coronary disease mortality}

Mortality from coronary heart disease evolved in three phases (fig $4 \Downarrow$ ). From 1980 to 1996 , mortality fell consistently (reduction of $8.8 \%, 0.5 \%$ per year). After the crisis in 1996-2002, mortality decreased sharply by $34.4 \%$ (6.5\% per year). After 2002, the rate of decline slowed to $7.4 \%$ (1.4\% per year), similar to pre-crisis rates.

\section{Stroke mortality}

Mortality from stroke mirrored the pattern of mortality from coronary heart disease, with a modest decrease of $6.9 \%$ lasting from 1980 to 2000 ( $0.4 \%$ per year) and a sharp fall between 
2000 and 2004 of $13.6 \%$ (5.3\% per year). From 2004 to 2010, mortality fell by $1.3 \%$ ( $0.01 \%$ per year, similar to pre-crisis rates).

\section{Cancer mortality}

Cancer mortality followed a distinctly different pattern to that observed in coronary heart disease, stroke, and diabetes, with two distinct phases (fig 4). From 1980 to 1996, a slight decrease of $2.4 \%$ in cancer mortality was observed $(0.1 \%$ per year $)$, which reverted to a slight increase of $5.4 \%$ in $1996-2010(0.5 \%$ per year).

\section{All cause mortality}

Mortality from all causes, as expected, was highly influenced by trends in coronary heart disease and stroke, showing three different phases (data not shown). A prolonged decrease in mortality of $1.7 \%$ from 1980 to 1996 (0.1\% per year) was followed a sharp decline of $10.5 \%$ from 1996 to 2002 (2.9\% per year). From 2002 to 2010, there has been a modest decrease of $2 \%$ ( $0.7 \%$ per year).

\section{Discussion}

During the deepest period of the economic crisis in Cuba, lasting from 1991 to 1995 , food was scarce and access to gas was greatly reduced, virtually eliminating motorised transport and causing the industrial and agricultural sectors to shift to manual intensive labour. This combination of food shortages and unavoidable increases in physical activity put the entire population in a negative energy balance, resulting in a population-wide weight loss of 4-5 kg. ${ }^{8}$ The decline in food availability was associated with a neuropathy outbreak in the adult population in 1993. ${ }^{24}{ }^{25}$ The Cuban economy started recovering in 1996 with a sustained growth phase from 2000 onwards. Since 1996, physical activity has slightly declined. By 2002, energy intake had increased above pre-crisis levels.

As a result of the above trends, by 2011, the Cuban population has regained enough weight to almost triple the obesity rates of 1995. This U shaped, population-wide pattern in body weight is historically unique because of several factors: the initial weight loss occurred in a population that had been well nourished previously, lasted for five years, and affected people at all initial levels of body mass index.

Diabetes trends could have been substantially influenced by these population-wide changes in body weight. Diabetes prevalence surged from 1997 onwards, as weight started to rebound. Diabetes incidence decreased during the crisis, reaching its lowest point in 1996. The largest economic recovery saw diabetes incidence peaking in 2004 and 2009

Five years after the start of the economic crisis in 1996, an abrupt downward trend was observed in mortality from diabetes, coronary heart disease, stroke, and all causes. This period lasted an additional six years, during which energy intake status gradually recovered and physical activity levels were progressively reduced; in 2002, mortality rates returned to the pre-crisis pattern. A particularly dramatic shift in diabetes mortality was observed: from 2002 to 2010 , the annual increase in diabetes mortality was similar to that before the crisis. Moreover, declining rates of coronary heart disease and stroke slowed to annual decreasing rates similar to those before the crisis.

\section{Comparison with other studies}

The effect of high risk, preventive approaches on diabetes or cardiovascular mortality has been extensively studied and has reported conflicting and non-conclusive results. For example, the Look AHEAD clinical trial, ${ }^{26}$ aimed at reducing cardiovascular risk associated with diabetes through weight reduction and exercise, has been prematurely terminated for lack of an effect on cardiovascular mortality. Other high risk approaches, such as the prevention and control of diabetes through massive screenings, has recently shown no improvements in diabetes, cardiovascular, or all cause mortality. ${ }^{27}$ Overall, it seems that high risk preventive approaches have either not produced a beneficial effect on cardiovascular mortality or diabetes control and mortality, or have been unsuccessful in reducing risk to a sufficient degree to warrant a conclusion.

The complementary pathway to disease prevention, the population approach, has received scant attention in the literature. To our knowledge, the effect of population-wide weight regain on diabetes and cardiovascular mortality has not been previously studied. Research on population-wide interventions has so far only studied modelling studies ${ }^{28}$ or small scale interventions. ${ }^{14}$

Research on weight cycling, described in obese individuals undergoing repeated attempts at weight loss followed by weight regain, has reported conflicting results: either an increase ${ }^{29-32}$ or no association with general mortality. ${ }^{33}$ Specifically, no association between weight cycling and diabetes incidence has been recorded ${ }^{34}{ }^{35}$ Since individual weight cycling usually refers to multiple weight changes over an extended period, those results might have limited relevance for the population experience of a single cycle of weight gain, loss, and regain that we report here.

As shown in our results, smoking levels were affected by the crisis. The number of cigarettes smoked per capita in Cuba decreased in the crisis years, only to slightly recover afterwards and remain stable thereafter. Smoking prevalence has continuously decreased during the past 15 years in Cuba. The role of tobacco in the development and control of diabetes has been recently studied; both active and passive smoking are associated with increased incidence. ${ }^{36}$ This association is dose dependent ${ }^{37}$; therefore, the decrease in smoking in Cuba during the crisis may have contributed to the decline in diabetes incidence in those years. The effects of decreasing smoking rates should drive down the rates of diabetes incidence and mortality in the long term. In this case, the observed decline in smoking rates during and after the crisis should cause a decrease in diabetes mortality in the last decade of our study. The increase in diabetes mortality from year 2002 seems to rule out smoking as a major confounding factor in the observed trends, although it could be masking the true size of the effect of changes in dietary and physical activity on diabetes mortality. This consideration is analogous for coronary heart disease and stroke, which should fall as smoking prevalence declines.

\section{Strengths and limitations of study}

Our study presents the first observation of a population-wide event of this magnitude and its subsequent effects on public health. Population-wide shifts in other risk factors, such as cholesterol and blood pressure, have been described in large scale prevention interventions, for example, the North Karelia and FINRISK studies. ${ }^{38}$ In the Cuban experience, the changes in population-wide body weight were adaptive responses to dietary energy availability and energy expenditure; therefore, 
it is not possible to separate these two effects on mortality patterns.

Other unique effects of this experience should also be considered. Problems with food production in Cuba led to the creation and expansion of urban agriculture, allowing citizens to buy fresh produce directly from farmers. Large public health campaigns in schools and communities are currently in place using community gardening as an effort to improve nutrition education and diet quality. ${ }^{39}$ During the crisis, the Cuban government acquired and distributed more than one million bicycles, which contributed to the population-wide increase in physical activity. ${ }^{39}$ These unique features of the Cuban experience make it to that degree non-comparable with other examples of economic crises. For example, previous research on the health consequences of the Great Depression in the US showed that banking suspensions (as a proxy for large scale economic decline) was not followed by a decrease in mortality. ${ }^{40}$ As noted previously, controversy persists over the net benefit of generalised weight loss in modern populations. ${ }^{41}$ As articulated by Geoffrey Rose, ${ }^{15}$ a key element of a prevention strategy for diseases in populations with near universal exposure to the causal risk factor is a downward shift in the overall mean. The data presented here confirm this theory. The Cuban experience shows that within a relatively short period, modest weight loss in the whole population can have a profound effect on the overall burden of diabetes. In Cuba, weight loss also had a major effect on trends in cardiovascular diseases and all cause mortality. Although obesity is an important risk factor for cancer, ${ }^{42}$ only modest changes in cancer mortality were observed. Our study has some important limitations. We had no data on diabetes incidence for most crisis years, and rates in the subsequent years showed wide fluctuations. Data for diabetes mortality were available for the whole study period, but might not have adequately represented the health burden of diabetes. Death certificates are subject to misclassification bias, although the parallel trends in cardiovascular and all cause mortality rule out substantial shifts away from diabetes to major illnesses that occurred at the same time - the most common of which would have been vascular in cause. The cyclic pattern of the observed trends makes a bias less likely, owing to widespread changes in coding of death certificates. Estimating dietary intake from food disappearance data has known limitations, but data from available dietary surveys for the years before, during, and after the special period were consistent with food disappearance data from the Food and Agriculture Organization. ${ }^{8}$

\section{Conclusions and policy implications}

We found that a population-wide loss of 4-5 kg in weight in a relatively healthy population was accompanied by diabetes mortality falling by half and mortality from coronary heart disease falling by a third. Furthermore, a rebound in body weight was associated with an increased diabetes incidence and mortality, and a deceleration of the decline in mortality from coronary heart disease. So far, no country or regional population has successfully reduced the distribution of body mass index or reduced the prevalence of obesity through public health campaigns or targeted treatment programmes. ${ }^{16}$ The latest reports in the US have documented a plateau in the epidemic curve of obesity in adults, ${ }^{43}$ children, and adolescents,${ }^{44}$ but the public health effects of these changes have not yet been reported. It is therefore not possible to compare the Cuba findings with other populations. Therefore, the generalisability of our findings is uncertain. Nonetheless, these data are a notable illustration of the potential health benefits of reversing the global obesity epidemic.

We would like to acknowledge our great respect and admiration for the Cuban people who faced extremely difficult social and economic challenges during the special period-and by making common cause against this tragedy held up with courage and dignity. This tragedy was "man made" by international politics and should never happen again to any population.

Contributors: MF and RC contributed to the original design. $\mathrm{PO}, \mathrm{MB}$, and $\mathrm{AM}$ organised and conducted data collection. UB conducted the statistical analyses. MF, UB, and RC carried on the systematic literature research. MF, UB, PO, BC, JFK, and $\mathrm{RC}$ were active in the interpretation of results. The manuscript was drafted by MF, UB, JFK, and RC, and reviewed by all authors. All authors have approved the final report. All authors had full access to the data in the study and take responsibility for its integrity and the accuracy of the data analysis. MF is the guarantor for this study.

Funding: No funding sources had any role in the decision to submit this manuscript or in its writing.

Competing interests: All authors have completed the Unified Competing Interest form at www.icmje.org/coi_disclosure.pdf (available on request from the corresponding author) and declare: no support from any organisation for the submitted work; no financial relationships with any organisations that might have an interest in the submitted work in the previous 3 years; no other relationships or activities that could appear to have influenced the submitted work.

Ethical approval: The ethics committee of the University of Medical Sciences, Cienfuegos, approved protocols.

Data sharing: No additional data available.

1 West KM. Epidemiology of diabetes and its vascular lesions. Elsevier North-Holland, 1978.

2 Obesity: preventing and managing the global epidemic. Report of a WHO consultation. World Health Organ Tech Rep Ser 2000;894:i-xii,1-253.

3 Olshansky SJ, Passaro DJ, Hershow RC, Layden J, Carnes BA, Brody J, et al. A potential decline in life expectancy in the United States in the 21st century. N Engl J Med 2005;352:1138-45.

4 Ford ES, Mokdad AH. Epidemiology of obesity in the Western Hemisphere. J Clin Endocrinol Metab 2008;93(11 suppl 1):S1-8.

5 Durazo-Arvizu RA, McGee DL, Cooper RS, Liao Y, Luke A. Mortality and optimal body mass index in a sample of the US population. Am J Epidemiol 1998;147:739-49.

6 Flegal KM, Graubard BI, Williamson DF, Gail MH. Excess deaths associated with underweight, overweight, and obesity. JAMA 2005;293:1861-7.

7 Capewell S, O'Flaherty M. Rapid mortality falls after risk-factor changes in populations. Lancet 2011;378:752-3.

8 Franco M, Orduñez P, Caballero B, Tapia Granados JA, Lazo M, Bernal JL, et al. Impact of energy intake, physical activity, and population-wide weight loss on cardiovascular disease and diabetes mortality in Cuba, 1980-2005. Am J Epidemiol 2007;166:1374-80.

9 Lazo M, Franco M, Cooper R, Orduñez P. Better health statistics: the Cuban experience. Lancet 2006;367:985-6.

10 Ríos Massabot NE, Fernández Viera RM, Jorge Pérez ER. [Medical registries in Cuba] Revista Cubana de Salud Pública 2005;31:345-52.

11 Borowy I. Similar but different: health and economic crisis in 1990s Cuba and Russia. Soc Sci Med 2011;72:1489-98.

12 World Bank. World Bank data: Cuba profile. 2012. http://data.worldbank.org/country/cuba.

13 Benet Rodríguez M, Morejón Giraldoni A, Espinosa Brito A, Landrove Rodríguez O, Peraza Alejo D, Orduñez García P. Factores de Riesgo para Enfermedades Crónicas en Cienfuegos, Cuba 2010. Resultados preliminares de CARMEN II. MediSur 2010;8:56-9.

14 Ezzati M, Riboli E. Can noncommunicable diseases be prevented? Lessons from studies of populations and individuals. Science 2012;337:1482-7.

15 Rose G. Sick individuals and sick populations. Int J Epidemiol 1985;14:32-8.

16 Franco M, Orduñez P, Caballero B, Cooper RS. Obesity reduction and its possible consequences: what can we learn from Cuba's Special Period? CMAJ 2008;178:1032-4.

17 Cooper RS, Orduñez P, Iraola Ferrer MD, Munoz JL, Espinosa-Brito A. Cardiovascular disease and associated risk factors in Cuba: prospects for prevention and control. $A m \mathrm{~J}$ Public Health 2006;96:94-101.

18 Keck CW, Reed GA. The curious case of Cuba. Am J Public Health 2012;102:e13-22.

19 Campion EW, Morrissey S. A different model-medical care in Cuba. N Engl J Med 2013;368:297-9.

20 Barceló A, Díaz O, Norat T, Mateo de Acosta O. [Diabetes mellitus en Cuba (1979-1989), I: variaciones relacionadas con edad y sexo]. Rev Cub Endocrinol 1993;4:59-66.

21 Arnold Y, Castelo L, Licea M, Medina I. [Comportamiento de indicadores epidemiológicos de morbilidad por diabetes mellitus en Cuba, 1998-2009]. Rev Peru Epidemiol 2012;16:6.

22 Espinosa-Brito A, Viera-Yaniz J, Chavez-Troya O, Nieto-Cabrera R. Death of the teaching autopsy: autopsy is a success story in Cuba. BMJ 2004;328:166.

23 National Cancer Institute. Joinpoint regression program. 2012. http://surveillance.cancer. gov/joinpoint/.

24 The Cuba Neuropathy Field Investigation Team. Epidemic optic neuropathy in Cuba—clinical characterization and risk factors. N Engl J Med 1995;333:1176-82. 


\section{What is already known on this topic}

The health effects of population-wide changes in body weight on a well nourished population with a functioning universal health system is unknown

Large reductions in diabetes and cardiovascular mortality were noted after the population-wide weight loss in Cuba, during the economic crisis of the early 1990 s

\section{What this study adds}

Body weight regain in the Cuban population was associated with an increase in diabetes prevalence, incidence, and mortality, as well as a deceleration in the previously declining rates of cardiovascular death

Small losses in body weight and prevention of body weight gain across the population could be a critical strategy in the prevention of non-communicable diseases

25 Orduñez-Garcia PO, Nieto FJ, Espinosa-Brito AD, Caballero B. Cuban epidemic neuropathy, 1991 to 1994: history repeats itself a century after the "amblyopia of the blockade". Am J Public Health 1996;86:738-43.

26 National Institutes of Health. Weight loss does not lower heart disease risk from type 2 diabetes. 2012. www.nih.gov/news/health/oct2012/niddk-19.htm.

27 Simmons RK, Echouffo-Tcheugui JB, Sharp SJ, Sargeant LA, Williams KM, Prevost AT, et al. Screening for type 2 diabetes and population mortality over 10 years (ADDITION-Cambridge): a cluster-randomised controlled trial. Lancet 2012;380:1741-8.

28 Barton P, Andronis L, Briggs A, McPherson K, Capewell S. Effectiveness and cost effectiveness of cardiovascular disease prevention in whole populations: modelling study. $B M J$ 2011;343:d4044

29 Arnold AM, Newman AB, Cushman M, Ding J, Kritchevsky S. Body weight dynamics and their association with physical function and mortality in older adults: the Cardiovascular Health Study. J Gerontol A Biol Sci Med Sci 2010;65:63-70.

30 Rzehak P, Meisinger C, Woelke G, Brasche S, Strube G, Heinrich J. Weight change, weight cycling and mortality in the ERFORT Male Cohort Study. Eur J Epidemiol 2007;22:665-73.

31 Taing $\mathrm{KY}$, Ardern $\mathrm{Cl}$, Kuk JL. Effect of the timing of weight cycling during adulthood on mortality risk in overweight and obese postmenopausal women. Obesity (Silver Spring) 2012;20:407-13.

32 Wannamethee SG, Shaper AG, Walker M. Weight change, weight fluctuation, and mortality. Arch Intern Med 2002:162:2575-80.

33 Stevens VL, Jacobs EJ, Sun J, Patel AV, McCullough ML, Teras LR, et al. Weight cycling and mortality in a large prospective US study. Am J Epidemiol 2012;175:785-92.

34 Field AE, Manson JE, Laird N, Williamson DF, Willett WC, Colditz GA. Weight cycling and the risk of developing type 2 diabetes among adult women in the United States. Obes Res 2004;12:267-74.

35 Waring ME, Eaton $\mathrm{CB}$, Lasater TM, Lapane $\mathrm{KL}$. Incident diabetes in relation to weight patterns during middle age. Am J Epidemiol 2010;171:550-6.

36 Houston TK, Person SD, Pletcher MJ, Liu K, Iribarren C, Kiefe Cl. Active and passive smoking and development of glucose intolerance among young adults in a prospective cohort: CARDIA study. BMJ 2006;332:1064-9.
37 Yeh HC, Duncan BB, Schmidt MI, Wang NY, Brancati FL. Smoking, smoking cessation, and risk for type 2 diabetes mellitus: a cohort study. Ann Intern Med 2010;152:10-7.

38 Vartiainen E, Laatikainen T, Peltonen M, Juolevi A, Mannisto S, Sundvall J, et al. Thirty-five-year trends in cardiovascular risk factors in Finland. Int $\mathrm{J}$ Epidemio 2010:39:504-18.

39 Borowy I. Degrowth and public health in Cuba: lessons from the past? J Clean Prod 2013;38:17-26.

40 Stuckler D, Meissner C, Fishback P, Basu S, McKee M. Banking crises and mortality during the Great Depression: evidence from US urban populations, 1929-1937. J Epidemiol Community Health 2012;66:410-9.

41 Cooper RS. Which factors confound or modify the relationship between body weight and mortality? Int J Obes (Lond) 2008;32(suppl 3):S47-51.

42 Colditz GA, Wei EK. Preventability of cancer: the relative contributions of biologic and social and physical environmental determinants of cancer mortality. Annu Rev Public Health 2012;33:137-56.

43 Ogden CL, Carroll MD, Kit BK, Flegal KM. Prevalence of obesity and trends in body mass index among US children and adolescents, 1999-2010. JAMA 2012;307:483-90.

44 Flegal KM, Carroll MD, Kit BK, Ogden CL. Prevalence of obesity and trends in the distribution of body mass index among US adults, 1999-2010. JAMA 2012;307:491-7.

\section{Accepted: 11 February 2013}

\section{Cite this as: BMJ 2013:346:f1515}

This is an Open Access article distributed in accordance with the Creative Commons Attribution Non Commercial (CC BY-NC 3.0) license, which permits others to distribute, remix, adapt, build upon this work non-commercially, and license their derivative works on different terms, provided the original work is properly cited and the use is non-commercial. See: http://creativecommons.org/licenses/by-nc/3.0/. 


\section{Table}

Table 1/ Basic sociodemographic and economic information on Cuba at various stages of economic crisis ${ }^{12}$

\begin{tabular}{lccccc} 
& $\mathbf{1 9 8 0 - 9 0 ^ { * }}$ & $\mathbf{1 9 9 1 - 9 5 †}$ & $\mathbf{1 9 9 6 - 9 9 \neq}$ & $\mathbf{2 0 0 0 - 1 0 \S}$ \\
\hline Total population (no of people) & 10129295 & 10784 & \multicolumn{5}{c}{106} & 11029 & 124 & 11233417 \\
\hline Total area $\left(\mathrm{km}^{2}\right)$ & +3.44 & -6.79 & +4.58 & +5.23 \\
\hline Yearly GDP growth (\%) & 3200 & 2397 & 2491 & 3597 \\
\hline Gross national income per capita (purchasing power parity; \$) & 12.66 & 10.27 & 11.41 & 13.56 \\
\hline Dietary energy consumption per capita (MJ) & 97 & 99 & 99.8 & 99.8 \\
\hline Adult literacy rate (\%) & 74.2 & 74.8 & 75.9 & 77.8 \\
\hline Mean life expectancy (years) & & &
\end{tabular}

$\$ 1=£ 0.66 ; € 0.77$.

*Before economic crisis.

†Special period.

łLate economic crisis/early economic recovery.

$\S$ Economic recovery.

I1 kcal $=0.00418 \mathrm{MJ}$ 


\section{Figures}

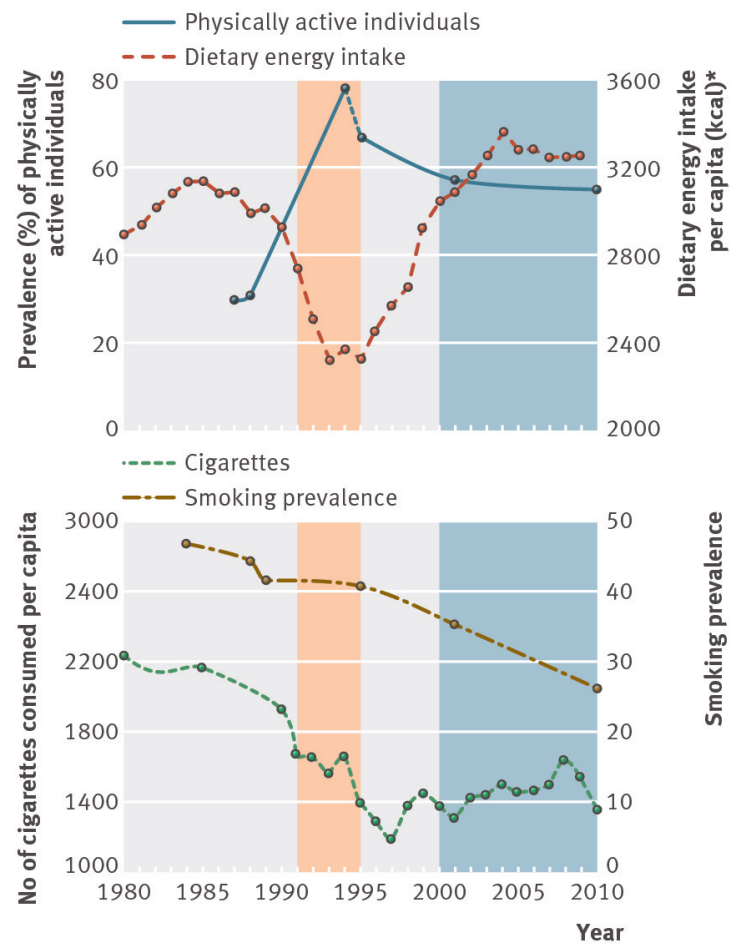

Fig 1 Physical activity, dietary energy intake, and smoking in Cuba, 1980-2010. Red shaded area=period of economic crisis; blue shaded area=period of economic recovery. Physical activity data recorded in 1987, 1988, and 1994 obtained from Havana surveys; data recorded in 1995, 2001, and 2010 come from national surveys. * 1 kcal=0.00418 MJ

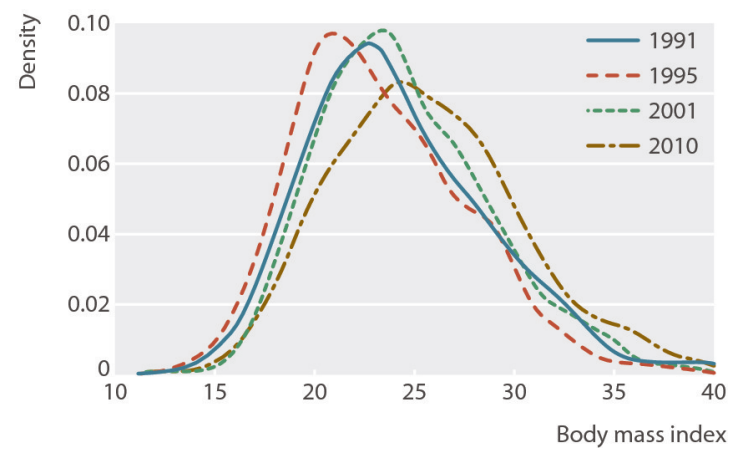

Fig 2 Distributions of body mass index as recorded by national surveys conducted in Cienfuegos in 1991, 1995, 2001, and 2010 


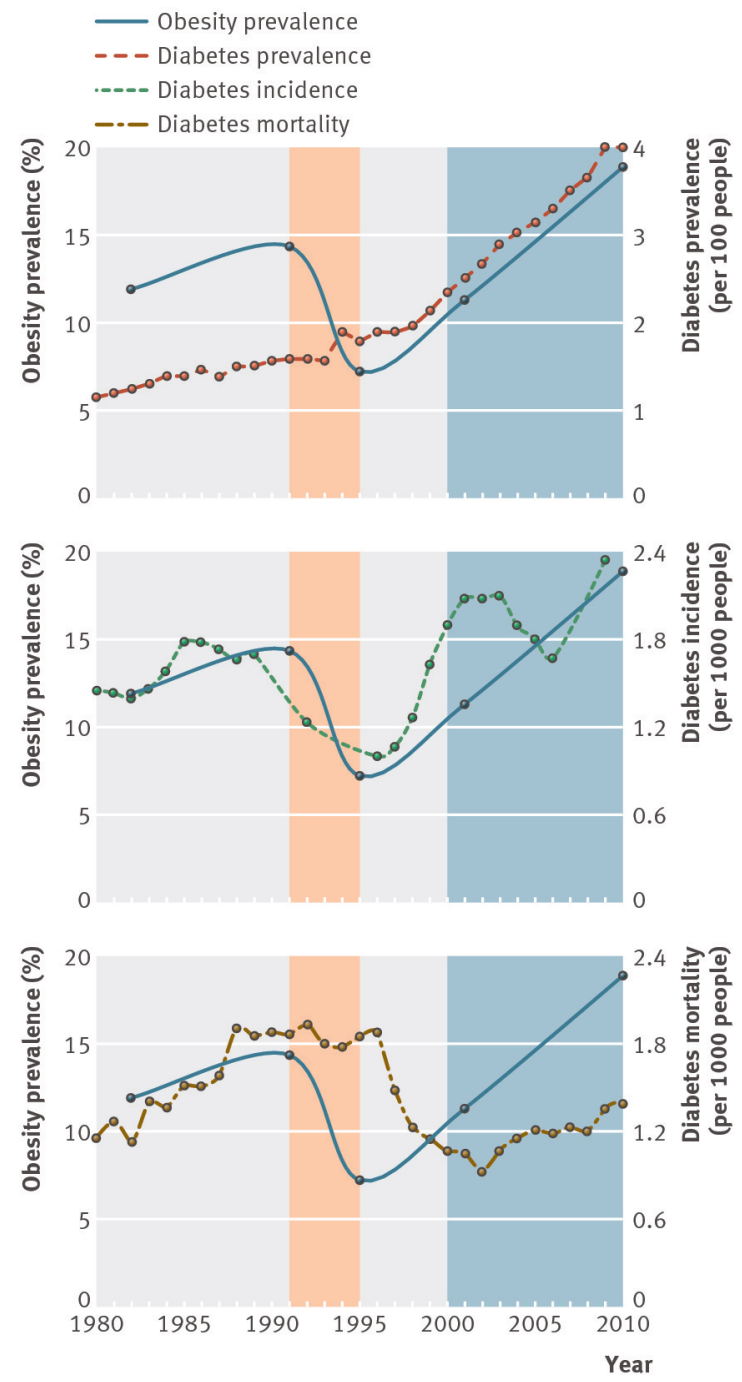

Fig 3 Prevalence of obesity and diabetes, incidence, and mortality in Cuba, 1980-2010. Red shaded area=period of economic crisis; blue shaded area=period of economic recovery. Diabetes prevalence increased by $2.93 \%$ per year from 1980 to 1997, and 6.27\% per year from 1997 to 2010 . Diabetes mortality increased by $5.85 \%$ per year from 1980 to 1989 , but fell by $0.68 \%$ per year from 1989 to 1996 and $13.95 \%$ per year from 1996 to 2002, before increasing by $3.31 \%$ per year from 2002 to 2010

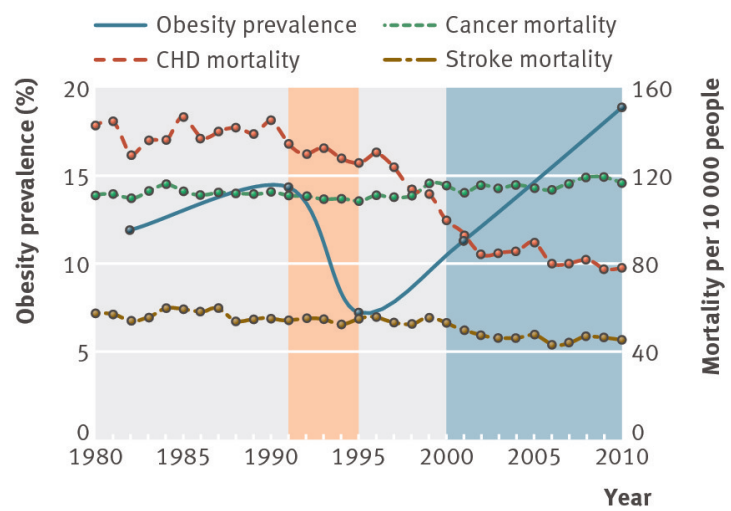

Fig 4 Obesity prevalence and coronary heart disease, cancer and stroke mortality in Cuba (1980-2010). Red shaded area=period of economic crisis; blue shaded area=period of economic recovery; $\mathrm{CHD}=$ coronary heart disease. $\mathrm{CHD}$ mortality decreased by $0.50 \%$ per year from 1980 to $1996,6.48 \%$ per year from 1996 to 2002, and $1.42 \%$ per year from 2002 to 2010. Cancer mortality decreased by $0.12 \%$ per year from 1980 to 1996 , but increased by $0.47 \%$ per year from 1996 to 2010. Stroke mortality fell by $0.39 \%$ per year from 1980 to $2000,5.03 \%$ per year from 2000 to 2004 , and $0.01 \%$ per year from 2004 to 2010 